\title{
С.В. Чубраков
}

\section{ОБЩАЯ СИСТЕМНАЯ ХАРАКТЕРИСТИКА УГОЛОВНО-ИСПОЛНИТЕЛЬНОГО ПРАВА В СВЕТЕ ПРОБЛЕМЫ ВЫЯВЛЕНИЯ ЕГО ПРИНЦИПОВ}

\begin{abstract}
Статья посвящена установлению принципов уголовно-исполнительного права с позиции системного подхода как системообразующих отношений данной отрасли. Дается необходимая для выявления принципов краткая системная характеристика самого уголовно-исполнительного права, в частности, рассматриваются его свойства, элементы, отношения.
\end{abstract}

Ключевые слова: принизипы уголовно-исполнительного права, свойства и элементы уголовно-исполнительного права, уголовно-исполнительное регулирование.

Проблема установления конкретного перечня принципов уголовно-исполнительного права напрямую зависит от того, что под этими принципами понимать. Общераспространенный в юридической литературе подход к рассмотрению принципов как «руководящих идей», «основных начал», «базовых требований» и тому подобных категорий с аморфными границами и содержанием порождает дальнейшие дискуссии уже по уяснению их смысла. $\mathrm{C}$ точки зрения формирования общепризнанного перечня принципов - это путь «в никуда», поскольку он повлек множество концепций исследователей (см. подробнее [1, с. 121-126]), недопустимое для такого базового правового понятия. Возможен и другой подход: взять за основу, например, понимание принципа как некоего требования и, определившись с тем, к чему будет это требование (к содержанию правовых предписаний, их созданию, реализации или к чему-то еще), оставить идею выявления какой-то объективной и общепризнанной системы этих принципов. Это позволит каждому автору продолжить выдвигать свои оригинальные предложения по их законодательному закреплению. Однако научная и практическая значимость подобного варианта развития сомнительна.

Между тем далеко не все имеющиеся возможности преодоления неоправданного субъективизма в вопросе принципов уголовно-исполнительного права (как и иных отраслевых принципов, так и российского права в целом) исчерпаны, и поиск объективных их оснований не должен быть прекращен. Выход из этой ситуации видится в выявлении иного методологически состоятельного подхода к определению категории «принцип», нежели тот, который общеприменим ныне. Одним из таких возможных подходов является системное понимание принципа как системообразующего отношения [2, с. 21-24; 3, с. 137-139], установление которого между элементами «вещи» (системы) влечет ее появление.

Подобный путь определения принципов уголовно-исполнительного права требует предварительной обстоятельной системной характеристики самого уголовно-исполнительного права, которая и станет предпосылкой последующего выявления данных отношений. Общая системная характеристика уго- ловно-исполнительного права не может быть дана без четкого определения его как самостоятельной «вещи» (системы) с выяснением его границ, в том числе отделяющих от иных «вещей» (систем). Для этого необходимо определиться, частью какой общности уголовно-исполнительное право является, каковы его свойства тождества (общегрупповые признаки) и свойства отличия (специфические признаки). Также важно, из каких элементов состоит само уголовно-исполнительное право и в какие промежуточные подсистемы могут объединяться его части. Bce это позволит перейти к поиску системообразующих отношений (принципов) уголовно-исполнительного права.

Поскольку уголовно-исполнительное право РФ является составной частью российского права, то есть ограничено его рамками, то оно должно обладать рядом основных свойств (с определенными уточнениями некоторых из них), которые отличают российское право от иных «вещей» (систем), в том числе и от «вещей» (систем) одной с ним группы: религии, морали, обычаев и т.п. Среди таких свойств можно выделить свойства социальной обусловленности, формальной определенности, нормативности, установленности или санкционированности российским государством, государственной принудительности, направленности на регулирование поведения (общественных отношений), а также способности регулирования «требуемого» поведения (общественных отношений).

Какие же уточнения и каких из перечисленных выше свойств российского права позволяют объединять определенный правовой материал в отдельную обособленную группу - в уголовно-исполнительное право? Представляется, что в первую очередь должно детализироваться свойство направленности на регулирование общественных отношений путем указания на некую однородность этих отношений. Обусловлено это тем, что еще со времен советских кодификаций деление права на отрасли традиционно производилось прежде всего по предмету их правового регулирования (по тому, на какую группу отношений направлено воздействие той или иной группы правил поведения). Однородность уголовно-исполнительных отношений (равно, как и 
всех иных) может выявляться только на основе неких заранее оговоренных параметров (признаков), позволяющих достаточно четко обособить их от всех иных. Таким образом, вопрос поиска параметров однородности, по сути, однопорядков с проблемой определения круга регулируемых уголовно-исполнительным правом отношений, то есть с проблемой предмета данной отрасли. Она была и продолжает оставаться весьма дискуссионной. Оставив в стороне нюансы данной дискуссии и вопросы установления признаков однородности регулируемых уголовно-исполнительным правом отношений (что является отдельной самостоятельной проблемой [4, с. 76-83]), в рабочем порядке такие отношения можно просто именовать отношениями по реализации мер уголовной ответственности, или, еще проще, - уголовно-исполнительными отношениями. Соответственно уточнение в свойство направленности на регулирование может звучать для уголовноисполнительного права в самом общем виде - как направленность на регулирование отношений по реализации мер уголовной ответственности или уголовно-исполнительных отношений.

Помимо уточнения свойства направленности на регулирование отношений, в уголовно-исполнительном праве должно быть уточнено и свойство установленности или санкционированности российским государством путем указания только на установленность, причем органами федерального уровня (что следует из п. «о» ст. 71 Конституции РФ, ч. 1 ст. 2 и ст. 4 УИК РФ).

При этом свойства российского права в виде государственной принудительности и способности регулирования «требуемого» поведения (общественных отношений) уголовно-исполнительному праву в полной мере не присущи, поскольку приобретать их оно может только в результате взаимодействия с иными отраслями (в частности, с уголовным и уголовно-процессуальным правом). Соответственно их частичное наличие можно приписывать уголовноисполнительному праву лишь с серьезными оговорками.

В итоге, уголовно-исполнительное право как отрасль права, то есть как самостоятельная «вещь» (система), будет характеризоваться, как минимум, наличием следующих свойств: социальной обусловленности, формальной определенности, нормативности, установленности государством в лице органов федерального уровня, направленности на регулирование уголовно-исполнительных отношений, а также частичной способности регулирования уголовно-исполнительных отношений и реализуемой не в полной мере государственной принудительности.

Следующий этап системной характеристики уголовно-исполнительного права - выявление и описание его минимально делимых элементов. В настоящее время, как и в науке советского исправительнотрудового права, преобладает позиция, согласно которой первичным элементом уголовно-исполнительного права следует считать уголовно-исполнитель- ную норму. Представления о норме, как минимальной части права, свойственны в целом и теории российского права, и отдельным правовым отраслям [5, с. $288 ; 6$, с. 417; 7, с. 192]. Минусы этой позиции настолько очевидны, что не дают покоя даже ее сторонникам, заставляя многих из них придумывать различные уточнения и «оговорки» $[8$, с. 81-82].

Вместе с тем существуют и иные точки зрения по этой проблеме. Мы разделяем представление о том, что минимальной частью права либо любой его отрасли должна рассматриваться не правовая норма (границы которой установить и описать порой весьма непросто), а конкретное правовое (нормативноправовое) предписание. Под ним в самом общем виде предлагается понимать закрепленное в соответствующем нормативно-правовом акте конкретное правило (модель) поведения, которое, в зависимости от вида образуемых им норм, имеет характер гипотезы, диспозиции или санкции [9, с. 27].

Если исходить из того, что российское право как систему составляют первичные элементы в виде правовых предписаний (а не отрасли, институты и даже не правовые нормы), то именно их следует считать минимально делимыми элементами и уголовно-исполнительного права (как части российского права). Но в данном случае с одним уточнением это не просто правовые предписания, а уголовно-исполнительные предписания. Соответственно следующая задача - определение тех свойств, которые будут отличать уголовно-исполнительные предписания от всех иных.

При решении этого вопроса нельзя не принимать во внимание того факта, что уголовно-исполнительные предписания являются частью правовых предписаний российского государства. Соответственно для уголовно-исполнительных предписаний должны быть характерны те же свойства, что и для правовых предписаний РФ, с определенным уточнением каких-либо из них. Представляется, что такие свойства правовых предписаний, как социальная обусловленность, формальная определенность, нормативность, взаимообеспеченность, порождаемость и тяга к объединению, характерны в целом и уголовно-исполнительным предписаниям. Уточнение касается (так же, как и в случае с уголовно-исполнительным правом) прежде всего свойств направленности на регулирование определенного общественного отношения или его части и установленности или санкционированности этих предписаний российским государством. Первое - за счет указания на то, что это не просто любое отношение или его часть, а отношение или его часть, входящее в предмет уголовно-исполнительного права (уголовно-исполнительное отношение). Второе - за счет ликвидации санкционированности, поскольку в силу сложившегося у российского законодателя подхода (ч. 1 ст. 2 и ст. 4 УИК РФ) уголовно-исполнительные предписания не могут содержаться в правовых обычаях, а также за счет дополнения установленности указанием на возможность осуществления этого только органами РФ фе- 
дерального уровня (п. «о» ст. 71 Конституции РФ, ч. 1 ст. 2 и ст. 4 УИК РФ).

Если обратиться к конкретным вариантам уголовно-исполнительных предписаний, то можно обнаружить, что они могут быть самого разнообразного вида (например, положения ст. 7, ч. 2 ст. 10, ч. 1 ст. 11 , ч. 1 ст. 25 , ч. 1 ст. 31 , ч. 1 ст. 75 УИК РФ и др.). Все эти и иные предписания можно группировать и систематизировать по разным основаниям.

Данные предписания, представляя собой, по сути, конкретные правила поведения, ориентированные на определенных субъектов, в различных ситуациях потенциально могут выполнять роль гипотез, диспозиций или санкций. То есть они могут быть самим правилом поведения, условием его существования («привязкой» к конкретной ситуации), либо негативными последствиями за его неисполнение (ответственностью в виде неких лишений и правоограничений, а также механизмом принудительного исполнения данного правила, когда это возможно). Эти функции они реализуют не одномоментно, а в разных отношениях. Так, если рассматривать предписание, закрепленное в ч. 1 ст. 31 УИК РФ о том, что осужденный к штрафу без рассрочки выплаты обязан уплатить штраф в течение 60 дней со дня вступления приговора суда в законную силу как диспозицию (основную модель поведения), то одним из его условий (гипотез) будет предписание, отраженное в ст. 7 УИК РФ - основаниями исполнения наказаний и применения иных мер уголовноправового характера являются приговор либо изменяющие его определение или постановление суда, вступившие в законную силу, а также акт помилования или акт об амнистии, а одним из последствий его невыполнения (санкцией) - правило ч. 2 ст. 32 УИК РФ о том, что в отношении осужденного, злостно уклоняющегося от уплаты штрафа, назначенного в качестве основного наказания, судебный пристав-исполнитель не ранее 10, но не позднее 30 дней со дня истечения предельного срока уплаты, указанного в ч.ч. 1 и 3 ст. 31 УИК РФ, направляет в суд представление о замене штрафа другим видом наказания в соответствии с ч. 5 ст. 46 УК РФ.

Здесь следует учитывать, что далеко не каждое предписание в разных отношениях даже потенциально может выполнять все три функции. Анализ ныне существующих предписаний показывает, что в основном они могут совмещать максимум две роли (диспозиции и гипотезы, диспозиции и санкции, а также санкции и гипотезы). Причем функцию диспозиции уголовно-исполнительное предписание должно быть способным реализовывать в обязательном порядке в том числе потому, что только в этой роли можно установить его отраслевую привязку к уголовно-исполнительному праву.

С теоретических позиций системного подхода невозможно существование уголовно-исполнительного предписания, не имеющего связи, как минимум, с двумя другими, выступающими для него условием его реализации и последствием несоблюде- ния закрепленной в нем модели поведения. По факту же в современном российском уголовно-исполнительном праве это встречается достаточно часто (равно как и в иных отраслях). По сути, такие правила, в силу отсутствия у них необходимых свойств правовых предписаний, не могут и не должны оцениваться в качестве таковых.

Кроме того, нередко гипотезой будет не просто какое-либо правило поведения или их совокупность (порой сложно поддающееся полному установлению), а его (их) нарушение. Причем вовсе не обязательно, чтобы это условие было предписанием уголовно-исполнительным. Оно вполне может относиться и к иной отрасли права (и таких случаев большинство).

Таким образом, установленные свойства уголовно-исполнительных правовых предписаний позволяют отделить от них те, которые их признакам (более точно - свойствам) в совокупности не соответствуют, но часть из них имеют. Причем те положения, которые имеют характер определений (раскрывают содержание каких-либо терминов), по общему правилу не должны рассматриваться в качестве самостоятельных правовых предписаний, а должны оцениваться как соответствующие части иных предписаний (вынесенные «за скобку»). Например, это применимо к положениям ч. 1 ст. 32 УИК РФ, гласящим, что злостно уклоняющимся от уплаты штрафа признается осужденный, не уплативший штраф либо часть штрафа в установленный ч.ч. 1 и 3 ст. 31 УИК РФ срок.

Далее попытаемся установить отношения, в которые вступают уголовно-исполнительные предписания, образовывая различные новые «вещи» (системы), и в первую очередь уголовно-исполнительное право. При этом уголовно-исполнительные предписания также участвуют в формировании и иных «вещей» (систем), в частности уголовно-исполнительных норм (которые должны быть расценены как промежуточные обязательные подсистемы уголовно-исполнительного права), а также уголовно-исполнительных институтов (которые, также являясь промежуточными подсистемами, в отличие от первых, не имеют обязательного характера). Этот аспект требует отдельного более детального анализа.

Учитывая общие положения философской триады (вещь, свойство и отношение) и системного подхода, можно утверждать, что соответствующие отношения, в том числе и системообразующие, получаются в результате преобразования свойств правовых предписаний при проецировании их на иные правовые предписания. Это требует выяснения того, какие же из свойств уголовно-исполнительных предписаний участвуют в процессе создания (путем преобразования в отношения, скрепляющие элементы) уголовно-исполнительного права.

Представляется, что для уголовно-исполнительного права типичными (так же, как и для любой иной гомогенной, совокупной системы) будут общесистемные отношения соединения (конъюнкции) 
уголовно-исполнительных предписаний по отношениям тождества их свойств. Так, совершенно очевидно, что к уголовно-исполнительному праву должно быть отнесено любое правовое предписание, обладающее свойствами уголовно-исполнительного. Например, создание соответствующими уполномоченными органами государственной власти правила о том, что наказание в виде обязательных работ может отбываться на предприятиях любой организационно-правовой формы и формы собственности, явно направлено на регулирование общественных отношений по реализации мер уголовной ответственности. И при наличии иных свойств уголовно-исполнительных предписаний оно будет отнесено к уголовно-исполнительному праву.

Помимо этого, данные отношения соединения будут дополняться, по нашему мнению, иными системообразующими отношениями, характерными как для уголовно-исполнительного права РФ, так и для российского права в целом. В качестве первых (отношений, характерных именно для уголовно-исполнительного права) будут выступать отношения направленности на регулирование уголовно-исполнительных отношений (которые возникают в процессе преобразования тождественных по наименованию свойств уголовно-исполнительных предписаний). В качестве вторых (отношений, характерных для российского права в целом) - отношения взаимообеспечения (также возникающие из идентичных по названию свойств) и отношения упорядоченности (в образовании которых, полагаем, участвуют прежде всего свойства социальной обусловленности).

Что касается отношений взаимообеспечения, то любое предписание, не состоящее в них, не может быть оценено как правовое в строгом смысле этого слова. При этом свойство правового предписания в виде взаимообеспеченности (которое при переложении на другое предписание трансформируется в отношение, установленное между ними) проявляется в необходимом обеспечении одного предписания другими предписаниями (как минимум, двумя). Последние на первоначальном (низшем) уровне будут условием его применения (гипотезой) и негативным последствием за его несоблюдение (санкцией в широком смысле слова), включающем в себя не только ответственность за неисполнение предписанной модели поведения, но и ее принудительную реализацию, когда это возможно. Также свойство взаимообеспеченности проявляется в одновременной способности правового предписания обеспечивать другие предписания, выступая в иных отношениях при формировании разных видов правовых норм их гипотезой или санкцией. Так, установить любое правило (модель) поведения в сфере исполнения мер уголовной ответственности возможно лишь тогда, когда будет оговорено условие применения этого правила и последствия за его несоблюдение. Конечно, в ряде ситуаций можно не создавать новых правил, а воспользоваться уже имеющимися. Из этого следует, что одно и то же предписание может быть гипотезой либо санкцией не только для какого-то одного предписания, выступающего диспозицией.

Немаловажно, что нахождение правовых предписаний в отношениях взаимообеспечения не ограничивается рамками исключительно уголовно-исполнительного права. Это отношение гораздо шире и может реализовываться в межотраслевом «пространстве».

Кроме того, свойство взаимообеспеченности проявляется и на иных системных уровнях взаимодействия правовых предписаний, когда не только отдельные предписания обеспечивают существование других, но и их группы, объединенные по заданным свойствам, взаимообеспечивают жизнь иных групп (например, это применимо к правовым институтам).

В российском праве, в том числе и в уголовноисполнительном праве, как говорилось выше, имеется немало случаев, когда некие модели поведения, претендующие на наличие статуса правовых предписаний, не находятся в отношениях взаимообеспечения с иными. Это позволяет говорить, что они не являются в строгом смысле слова правовыми предписаниями в силу отсутствия у них необходимых свойств последних.

Что касается отношений упорядоченности, то они могут иметь различные варианты проявления: и отношения «взаимопомощи», и отношения согласованности, непротиворечия друг другу, и отношения соподчинения, иерархичного подчинения, и отношения неналожения друг на друга и др. Это обусловлено как тем, что данные отношения сами довольно разнообразны по своему содержанию, так и тем, что уголовно-исполнительные предписания могут и должны находиться в этих отношениях не только с другими предписаниями в рамках данной отрасли, но и со множеством иных, не уголовно-исполнительных предписаний.

Например, все уголовно-исполнительные предписания должны быть субординированы, иерархично соподчинены по отношению к конституционноправовым предписаниям, которые в силу установленных в РФ правил обладают высшей юридической силой по отношению ко всем иным. Соответственно субординация должна быть произведена с соблюдением одного из главных требований: отмеченные предписания не должны противоречить конституционным, то есть между ними должна быть установлена такая разновидность отношений субординации, как отношения непротиворечия (согласованности). Это касается системы органов, уполномоченных к их созданию, требований по соблюдению запрета унижения чести и достоинства, требований по соблюдению гарантированных конституционных прав человека и гражданина и т.п.

Очевидно, что уголовно-исполнительные предписания также должны ставиться в отношения упорядоченности с уголовно-процессуальными и уголовно-правовыми предписаниями (в основном в отношения непротиворечия, неналожения и недубли- 
рования). К сожалению, это не всегда можно видеть в рамках практики российского законодателя.

Отдельные проблемы реализации таких системообразующих отношений уголовно-исполнительного права и российского права в целом, как отношений взаимообеспечения и упорядоченности, тесно связаны с разведением границ уголовно-исполнительных отношений с границами иных «смежных» отраслей права, то есть с реализацией системообразующего отношения в виде направленности на регулирование уголовно-исполнительных отношений. Причем проблему последнего составляет во многом вопрос об установлении параметров (признаков) однородности уголовно-исполнительных отношений, позволяющих четко очертить их круг.

Таким образом, в качестве общего принципа (при понимании его как системообразующего отношения) уголовно-исполнительного права будет выступать, по нашему мнению, принцип соединения его предписаний по отношениям тождества их свойств. Конкретным же принципом, характерным именно уголовно-исполнительному праву, будет направленность на регулирование уголовно-исполнительных отношений. При этом уголовно-исполнительному праву свойственны и общеправовые принципы взаимообеспечения и упорядоченности.

Немаловажно, что все данные принципы характеризуют в основном «технико-юридические» аспекты взаимодействия элементов данной отрасли (типичные в целом и для иных групп, объединений правовых предписаний), не вскрывая сущностных, характерных для предписаний этой группы особенностей. Это актуализирует необходимость установления принципов иных категорий, в частности уголовно-исполнительного регулирования, которые, вполне возможно, и позволят увидеть сущностные особенности создания и претворения в жизнь уголовно-исполнительных предписаний.

\section{ЛИТЕРАТУРА}

1. Чубраков С.В. Краткая характеристика современных взглядов на систему принципов уголовно-исполнительного права // Ученые записки. Вып. 3. Сборник научных трудов Западно-Сибирского филиала Российской академии правосудия (г. Томск). Томск: Изд-во ЦНТИ, 2009. С. 121-126.

2. Уткин В.A. Понятие «принцип отрасли права» и его значение для дискуссии о самостоятельности исправительнотрудового права // Вопросы повышения эффективности борьбы с преступностью: сб. статей. Томск, 1979. С. $21-24$.

3. Чубраков C.B. Содержание категории «принцип» в уголовно-исполнительном праве в аспекте системного подхода // Вестник Томского государственного университета. 2011. № 343. С. 137-139.

4. Чубраков C.B. Параметры однородности отношений в сфере уголовно-исполнительного правового регулирования // Вестник Томского государственного университета. Право. 2012. № 3 (5). С. $76-83$.

5. Алексеев С.С. Общая теория права: учебник. 2-е изд., прераб. и доп. М.: ТК Велби, Изд-во Проспект, 2008.576 с.

6. Венгеров А.Б. Теория государства и права: учеб. для юрид. вузов. 6-е изд., стер. М.: Изд-во «Омега-Л», 2009. 607 с.

7. Капустина М.А. Норма как элемент системы права // Актуальные проблемы теории и истории права и государства: Сб. ст., посвященный памяти профессора В.В. Посконина / под общ. ред. О.В. Поскониной. Ижевск: Изд. дом «Удмуртский университет», 2008. С. 191-203.

8. Лейст О.Э. Сущность права. Проблемы теории и философии права / под ред. В.А. Томсинова. М.: Зерцало, 2008. 452 с.

9. Ходукин Д.В. Юридические предписания. Иркутск: Изд-во БГУЭП, 2006. 195 с.

\section{GENERAL SYSTEM CHARACTERISTIC OF THE PENAL LAW IN TERMS OF ITS PRINCIPLES}

Russian Journal of Criminal Law, 2015, no. 2(6), pp. 89-94. DOI 10.17223/23088451/6/17

Chubrakov Sergey V., Tomsk State University (Tomsk, Russian Federation). E-mail: chubrakov@mail.ru

Keywords: principles of penal law, properties and elements of penal law, penal regulation.

The article establishes the principles of penal law as the framework relations in this branch. It provides a brief description of the system of penal law, in particular, its properties, elements and relations that are necessary for specifying its principles.

The problem of the list and content of legal principles, including those in the penitentiary law, is one of the most topical and controversial in the legal science. The popular interpretation of legal principles as "guiding ideas", "first principles", "basic requirements" and similar categories is unproductive: their ambiguous content and amorphous boundaries gives rise to discussions on their meanings.

The author proposes a different approach to the identification of the penal law principles. This approach is based on a systemic understanding of the category "principle" as framework relations, the establishment of which between the elements of the "thing" implies its appearance. This approach to defining the penal law principles requires prior thorough systemic characterization of the penal law itself, which will be a prerequisite for the subsequent identification of these relations. In this regard, the article describes the properties, elements and framework relations of the penal law, with its properties specified on the on the basis of the Russian law that limits its scope. The primary elements of the penal law include penal (normative) requirements that constitute the norms of the penal law. The analysis of the relevant relations that arise among these elements leads the author to the conclusion that the framework character allowing the elements to be identified as principles can be found in the following relations: combination of requirements according to the identity of their properties, focus on regulation of penal relations, mutual provision and sequence.

A brief description of the above-stated principles shows that they refer only to "technical" aspects of the interaction of the elements in this branch (generally typical for other branches). However, they do not reveal the essential features specific to the requirements of the group. This raises the problem of establishing the principles of other legal categories, in particular those of penal regulation that will possibly allow seeing the essential features of the establishment and implementation of penal provisions. 


\section{REFERENCES}

1. Chubrakov, S.V. (2009) Kratkaya kharakteristika sovremennykh vzglyadov na sistemu printsipov ugolovno-ispolnitel'nogo prava [A brief description of the modern views on the system of penal law principles]. Uchenye zapiski. Sbornik nauchnykh trudov Zapadno-Sibirskogo filiala Rossiyskoy akademii pravosudiya. Issue 3. Tomsk: TsNTI. pp. 121-126.

2. Utkin, V.A. (1979) Ponyatie "printsip otrasli prava" i ego znachenie dlya diskussii o samostoyatel'nosti ispravitel'notrudovogo prava [The concept of "principle of abranch of law" and its implications for the debate on the independence of correctional labour law]. In: Sviridov, M.K., Remenson, A. L. \& Filimonov, V.D. (eds) Voprosy povysheniya effektivnosti bor'by s prestupnost'yu [On improving the efficiency of crime prevention]. Tomsk: Tomsk State University. pp. 21-24.

3. Chubrakov, S.V. (2011) The content of the category "principle» in the penal executive law under the systems approach. Vestnik Tomskogo gosudarstvennogo universiteta - Tomsk State University Journal. 343. pp. 137-139. (In Russian).

4. Chubrakov, S.V. (2012) Relations of uniformity parameters in penitentiary legal regulation. Vestnik Tomskogo gosudarstvennogo universiteta. Pravo - Tomsk State University Journal of Law. 3(5). pp. 76-83. (In Russian).

5. Alekseev, S.S. (2008) Obshchaya teoriya prava [The General Theory of Law]. 2nd ed. Moscow: Velbi, Prospekt.

6. Vengerov, A.B. (2009) Teoriya gosudarstva i prava [The Theory of State and Law]. 6th ed. Moscow: Omega-L.

7. Kapustina, M.A. (2008) Norma kak element sistemy prava [The norm as a legal system element]. In: Poskonina, O.V. (ed.) Aktual'nye problemy teorii $i$ istorii prava $i$ gosudarstva [Topical problems of theory and history of law and state]. Izhevsk: Udmurt University. pp. 191-203.

8. Leyst, O.E. (2008) Sushchnost' prava. Problemy teorii i filosofii prava [The essence of law. Problems of the theory and philosophy of law]. Moscow: Zertsalo.

9. Khodukin, D.V. (2006) Yuridicheskie predpisaniya [Legal regulations]. Irkutsk: Baikal State University of Economics and Law. 